\title{
Degree of conversion of resin-cements (light-cured/dual-cured) under different thicknesses of vitreous ceramics: systematic review
}

\author{
Melissa David-Pérez, Juan P. Ramírez-Suárez, Federico Latorre-Correa, Andrés A. Agudelo-Suárez* \\ Facultad de Odontología, Universidad de Antioquia. Medellín, Colombia
}

\begin{abstract}
Purpose: This systematic review synthesized and analyzed the scientific evidence on the degree of conversion (DC) obtained by Fourier-transform infrared spectroscopy (FTIR) of light-cured and dual-cured resinous cements, photopolymerized under different thicknesses of vitreous ceramics.

Study selection: The study protocol of this systematic review was registered at the International Prospective Register of Systematic Reviews (PROSPERO) (CRD42017069319). A comprehensive search (PubMed/MEDLINE, Scopus, EMBASE, and LILACS) was performed for papers including an in vitro design and indexed from January 2007 to December 2020 according to the study purposes. A quality appraisal (specific instrument) and descriptive analysis of the articles that met the inclusion criteria were conducted.

Results: Nine included studies were analyzed. Two of them used feldspathic ceramics, six used lithium disilicate, and one used both (comparing different types and opacities of ceramics). Three studies found a higher DC in dual cements, while one did not find any significant differences, and five studies found a higher DC in light-cured resin cements. Light-cured cements showed a better DC in relation to dual-cured cements in vitreous ceramic restorations with thicknesses up to $2 \mathrm{~mm}$. Conclusion: According to the findings, the use of good photoactivation is the most relevant variable to achieve an adequate $D C$ in light-cured and dual-cured resin cements. The use of vitreous ceramic restorations with a thickness of less than $2 \mathrm{~mm}$ (light-curing cements) shows a better DC. Standardized in vitro studies are required to generate accurate scientific evidence.
\end{abstract}

Keywords: Resin cements, Dental curing lights, Self-curing of dental resins, Dental veneers, Systematic review

\section{Introduction}

The physical and optical properties of ceramics make them the material of choice for patients with high esthetic and functional expectations because of their color stability, wear resistance, and biocompatibility. [1] The success of restorative treatment with ceramics depends on the mechanical integrity of the material and the quality of the adhesive interface. [1-4] This process involves factors such as the adhesive system, type of cement (composition and activation mode), type of light-curing, polymerization protocol, and characteristics of the ceramic. [5]

The most commonly used materials for cementation are resin cements because of their optimal physicochemical properties, such as their variability in tones, adequate flexural and compressive strength, superior retention, and high fracture resistance. $[1,6,7]$ These materials are composed of a polymeric matrix based on dimethacrylate monomers, filler particles, and pigments. [1] Resin ce-

DOI: https://doi.org/10.2186/jpr.JPR_D_20_00090

*Corresponding author: Andrés A. Agudelo-Suárez, Facultad de Odontología, Universidad de Antioquia, Calle 70 \# 52-21, Medellín 050010, Colombia.

E-mail address: oleduga@gmail.com, alonso.agudelo@udea.edu.co

Copyright: @ 2021 Japan Prosthodontic Society. All rights reserved. ments are classified according to the type of filling, mode of activation (light, chemical, and dual curing), and the bonding mechanism (self-etching and total etch). [7] The light-curing cements can only be activated in the presence of a light source that stimulates photoinitiators, initiating the polymerization reaction. [3] Some advantages of this mechanism are color stability, adequate working time, and easier removal of excess cement prior to photoactivation. $[1,8]$ The polymerization reaction can be affected by the composition of each product (type of monomer, content of inorganic particles, and possible interactions between the bonding system and cement) [7] and by extrinsic factors such as translucency and thickness of the indirect restoration, in addition to the temperature, type, and amount of light energy received. [7,9-11]

To overcome the limitations of light-cured cements, dual-cured cements were designed to ensure polymerization in regions where light curing is complex. [1,9,12-15] These systems are composed of a catalyst paste of benzoyl peroxide (initiator) and the base paste containing a light-curing resin cement. $[1,16]$ The free radicals formed by the chemical reaction (tertiary amines, benzoyl peroxide) compensate for the lack of free radicals resulting from the light-activated initiation system (aliphatic amines, photoinitiator). Dual-cured resin cements may have a reduction in color stability because of the possi- 
bility of oxidation that occurs in the components involved in chemical curing (tertiary amines). [1]

The degree of conversion (DC) of resinous materials refers to the number of monomer units that react to form polymers, which determines the physical and mechanical properties of each material, $[3,7,8]$ its biocompatibility, strength, elastic modulus, hardness, and solubility. $[1,7,11,17,18]$ The literature reports that a clinically accepted DC should be between 60 and $75 \%$. It is commonly believed that hardness is strongly correlated with the DC. Many studies have used Knoop or Vickers hardness tests to determine the DC, but given that most mechanical properties of resin cements are influenced by several characteristics (type and composition of resin, type of filler, filler loading, polymerization mode, chemical structure of the monomers, and the type and density of the cross-links), the absolute microhardness should not be compared with the DC values. $[3,5,6,19]$ The most precise techniques to determine qualitatively and quantitatively the number of carbon-carbon $(C=C)$ double bonds present in the resin matrix are nuclear magnetic resonance (NMR), high performance liquid chromatography (HPLC), gel permeation chromatography (GPC), multiple internal reflection (MIR), infrared spectroscopy, and Fouriertransform infrared spectroscopy (FTIR). [18] FTIR is one of the most commonly used tests owing to its fast scanning capacity, high wavelength, better resolution, stability, and accuracy. [7]

The DC can be affected by the same factors involved in the polymerization reactions. Nevertheless, there is a lack of consensus regarding the relationship between the DC and the thickness of ceramic restorations and the polymerization mode of the resin cement used. Runnacles et al. [20] demonstrated that the DC of light-cured resin cement is affected by the thickness and type of ceramic used when cementing restorations larger than $1.5 \mathrm{~mm}$. Faria $\mathrm{E}$ et al. [21] indicated that the increased thickness of the IPS Empress Esthetic ceramic $(0.5,1$, and $2 \mathrm{~mm})$ resulted in radiation decrease using two LED units; however, no direct relationship between the radiation loss and DC was observed in ceramic thicknesses of less than $1.5 \mathrm{~mm}$.

Accordingly, this systematic review aims to synthesize and analyze the scientific evidence on the DC obtained by FTIR of light-cured and dual-cured resinous cements, photopolymerized under different thicknesses of vitreous ceramics, in order to guide clinicians in the selection of cement in different situations.

\section{Methods}

\subsection{Study design}

A systematic review was conducted, and this paper was written according to the updated PRISMA 2020 statement. [22]

\subsection{PICO question and eligibility criteria}

For this systematic review, the following eligibility criteria were applied according to the PICO question: What is the scientific evidence regarding the DC obtained using either light-curing or dualcuring resinous cements in vitreous ceramic restorations?

- Study design: studies conducted in vitro with practical relevance to dental procedures. This review focused on publications in English, Spanish, and Portuguese from January 2007 to December 2020. The studies were selected based on the following criteria: articles that considered polymerization under vitreous ceramic substrates with determined thicknesses, publications using dual- and light-curing resin cements as cementation materials, and studies that included evaluation of the DC of resinous cement using FTIR.

- Participants: indirect dental restorations (dual-curing and lightcuring resinous cements)

- Interventions/control: geometric shapes (discs) of the vitreous ceramic material. Studies that compared resinous cements of both types of polymerization (light and dual) under the thicknesses of the ceramic material were selected.

- Exclusion criteria: studies conducted on animals, other types of observational/intervention studies, narrative/systematic reviews and other types of theoretical papers. Furthermore, studies that focused on other dental materials or cements for other dental purposes were excluded.

- Outcome: DC obtained in the cements.

\subsection{Information sources and search strategy}

Table 1 shows the main characteristics related to the database sources, search equations, and definitions employed for the search strategy according to the mesh terms/thesaurus.

\subsection{Study Selection}

Two reviewers (MDP and JPR) independently searched for titles and abstracts of potentially eligible articles. If the information met the eligibility criteria, the article was selected for full reading. In addition, the reviewers (MDP and JPR) checked the reference list of the selected articles to find further studies that were not identified in the initial searches. All articles selected for inclusion in the review were processed for data extraction by the same reviewers. Disagreements were resolved by discussion and consultation with at least one other member of the research team (AAAS and/or FLC).

\subsection{Critical appraisal of the selected studies}

Two of the authors (MDP and JPR) reviewed the quality of the papers. To guarantee the quality evaluation process, a pilot test was conducted with five articles, and a simple concordance index was calculated, with a score of $90 \%$. This process was methodologically supported by two other authors: the first (AAAS), a Ph.D. in public health, with experience in systematic reviews, and the second author (FLC) with thematic experience in prosthodontics.

The analysis of the quality of the studies was performed by MDP and JPR, using the parameters cited in the guidelines for reporting pre-clinical in vitro studies on dental materials: [23] (Item 1) abstract, (Item 2a, Item 2b) introduction, background, and objective, (Item 3) methods: intervention, (Item 4) outcomes, (Item 5) sample size, (Item 6) randomization: sequence generation, (Item 7) allocation concealment mechanism, (Item 8) implementation, (Item 9) blinding, (Item 10) statistical methods, (Item 11) results: outcomes and estimation, (Item 12) discussion: limitations, (Item 13) other information: funding, (Item 14) protocol. Both reviewers conducted the analyses independently, and disagreements were resolved through discussion.

\subsection{Data items and synthesis methods}

The following data were recorded for each study: author, year and country of publication, type of vitreous ceramic, shade of ceramic material, thickness of samples, resinous cement used, thickness of cement, activation mode, type of lamp, time used for polymeriza- 
Table 1. Characteristics of the search strategy used for the systematic review

\begin{tabular}{ll}
\hline Type of literature: & Source: \\
Published material & - PubMed-Medline \\
& - Scopus \\
& - EMBASE (The Excerpta Medica Database) \\
& - LILACS (Latin-American scientific literature in health sciences)
\end{tabular}

Search Terms: Full strategy for all databases

- PubMed: ((((“"Curing Lights, Dental"[Mesh]) OR "Self-Curing of Dental Resins"[Mesh]) OR resin cements[Title/Abstract]) OR ((()(((“Dental Veneers"[Mesh]) OR luting cement) OR “Dental Cements"[Mesh]) OR “Dental Prosthesis”[Mesh]) OR dental crowns) OR "Crowns"[Mesh]) OR "Dual Zement" [Supplementary Concept]))) AND (((degree conversion[Title/Abstract]) OR ("Hardness"[Mesh] OR "Hardness Tests"[Mesh])) OR "Polymerization"[Mesh]) OR polymerization[Title/Abstract]) Filters: published in the last 14 years - Scopus: dental AND curing AND light OR dental AND curing AND light OR dental AND self-curing OR dental AND self-curing OR resin AND cement OR resin AND cement OR dental AND veneer OR dental AND veneer OR cementation OR cementationor AND cementation OR tooth AND crown OR dual AND cement OR dual AND cement) AND (degree AND conversion OR hardness OR hardness AND tests OR polymerization) AND (LIMIT-TO (PUBYEAR, 2020) OR (LIMIT-TO (PUBYEAR, 2019) OR LIMIT-TO (PUBYEAR, 2018) OR (LIMIT-TO (PUBYEAR, 2018) OR LIMIT-TO (PUBYEAR, 2017) OR (LIMIT-TO (PUBYEAR, 2017) OR LIMIT-TO (PUBYEAR, 2016) OR LIMIT-TO (PUBYEAR, 2015) OR LIMIT-TO (PUBYEAR, 2014) OR LIMIT-TO (PUBYEAR, 2013) OR LIMIT-TO (PUBYEAR, 2012) OR LIMIT-TO (PUBYEAR, 2011) OR LIMIT-TO (PUBYEAR, 2010) OR LIMIT-TO (PUBYEAR, 2009) OR LIMIT-TO (PUBYEAR, 2008) OR LIMIT-TO (PUBYEAR, 2007)) AND (LIMIT-TO (DOCTYPE, “ar")) AND (LIMIT-TO (LANGUAGE, “English”) OR LIMIT-TO (LANGUAGE, “Portuguese”) OR LIMIT-TO (LANGUAGE, "Spanish")

- EMBASE: ('dental curing light'/exp OR 'dental curing light' OR 'dental self-curing'/exp OR 'dental self-curing' OR 'resin cement'/exp OR 'resin cement' OR 'dental veneer'/exp OR 'dental veneer' OR 'cementation' OR 'cementation'/exp OR cementation OR 'tooth crown'/exp OR 'tooth crown') NOT ('dual cement'/exp OR 'dual cement') AND [2007-2020]/py AND (degree AND ('conversion' OR 'conversion'/exp OR conversion) OR 'hardness' OR 'hardness'/exp OR hardness OR (('hardness' OR 'hardness'/exp OR hardness) AND tests) OR 'polymerization' OR 'polymerization'/exp OR polymerization) AND [embase]/lim

- For the other database (LILACS), the strategy was adapted accordingly to the specific thesaurus and free terms. degree of conversion AND (db:(“BBO")) AND (year_cluster: [2007 TO 2020])

\section{Definitions provided Definitions according to MeSH}

for the databases

- Curing Lights, Dental: Light sources used to activate polymerization of light-cured DENTAL CEMENTS and DENTAL RESINS. Degree of cure and bond strength depends on exposure time, wavelength, and intensity of the curing light.

- Self-Curing of Dental Resins: The hardening or polymerization of bonding agents (DENTAL CEMENTS) via chemical reactions, usually involving two components. This type of dental bonding uses a self-cure or dual-cure system.

- Dental Veneers: The use of a layer of tooth-colored material, usually porcelain or acrylic resin, applied to the surface of natural teeth, crowns, or pontics by fusion, cementation, or mechanical retention.

- Dental Cements: Substances used to bond COMPOSITE RESINS to DENTAL ENAMEL and DENTIN. These bonding or luting agents are used in restorative dentistry, ROOT CANAL THERAPY; PROSTHODONTICS; and ORTHODONTICS.

- Dual cement: [Supplementary Concept]: a dual-curing luting composite resin

- Hardness Tests: A test to determine the relative hardness of a metal, mineral, or other material according to one of several scales, such as Brinell, Mohs, Rockwell, Vickers, or Shore.

- Polymerization: Chemical reaction in which monomeric components are combined to form POLYMERS.

tion, and the study's results. In addition, we performed a qualitative synthesis of the most relevant results for each study included in this systematic review. No additional analyses, such as meta-analysis and subgroup tests, were carried out considering the nature of the study design (in vitro), and the characteristics of the studies included. This decision was made through a discussion by the research team.

\section{Results}

\subsection{Study selection}

The initial search resulted in 2939 records. After eliminating duplicates, 2749 records were selected for revision of title and abstract, 2451 were excluded, 110 articles were selected for full reading, and finally, 9 publications were included. $[1,3,5-7,18,24-26]$ The reasons for exclusion are shown in Figure 1.

\subsection{Quality appraisal of the included studies}

The evaluation of the quality of the studies is reported in Table 2, where the parameters reported less frequently were allocation, concealment mechanism, implementation, blinding, limitations, funding, and protocol.

\subsection{Main characteristics of the included studies}

Table 3 summarizes the main characteristics of the included studies. All studies included in this report were performed in vitro. Two studies used feldspathic ceramic, $[1,18]$ one study used feldspathic ceramic and lithium disilicate pressed, [5] and six studies used only lithium disilicate. [3,6,7,24-26] Specifically, Cho et al. [6] and de Jesus et al. [25] used pressed disilicate (e.max press). Scotti et al., [3] Donmez and Yucel, [24] and Liporoni et al. [26] used mechanized disilicate (e.max CAD). Alkhudhairy et al. [7] did not report the tablet used. The DC of light- and dual-cured resin cements was evaluated by FTIR for thicknesses from $0.3 \mathrm{~mm} \mathrm{[6]} \mathrm{to} 2 \mathrm{~mm}$. [5] Another study evaluated the DC of a dual cement base paste. [1] The minimum thickness of the cement used was $50 \mu \mathrm{m},[18]$ and the maximum was $1,000 \mu \mathrm{m}$. [1,7] Only one study did not report the thickness of the cement film. [6]

Eight studies used mylar strips between the cement and the disc to obtain a smooth layer of the cement and separate it from the ceramic $[1,3,5-7,18,25,26]$ and one study used a glass plate between the ceramic and cement layers. [24] Eight studies used LED curing lamps, [3,5-7,18,24-26] and one study used a halogen lamp. [1] The lamps used were Demetron II-Kerr, [18] Optilux 501-Kerr, [1] Demi Plus-Kerr, [6] Translux Power Blue-Heraeus-Kulzer, [5] Bluephase, [24-26] Polywave VALO-Ultradent, [3] and Woodpecker I [7] with powers of 600 $\mathrm{mW} / \mathrm{cm}^{2}, 800 \mathrm{~mW} / \mathrm{cm}^{2}, 900 \mathrm{~mW} / \mathrm{cm}^{2}, 1000 \mathrm{~mW} / \mathrm{cm}^{2}, 1200 \mathrm{~mW} / \mathrm{cm}^{2}$, 

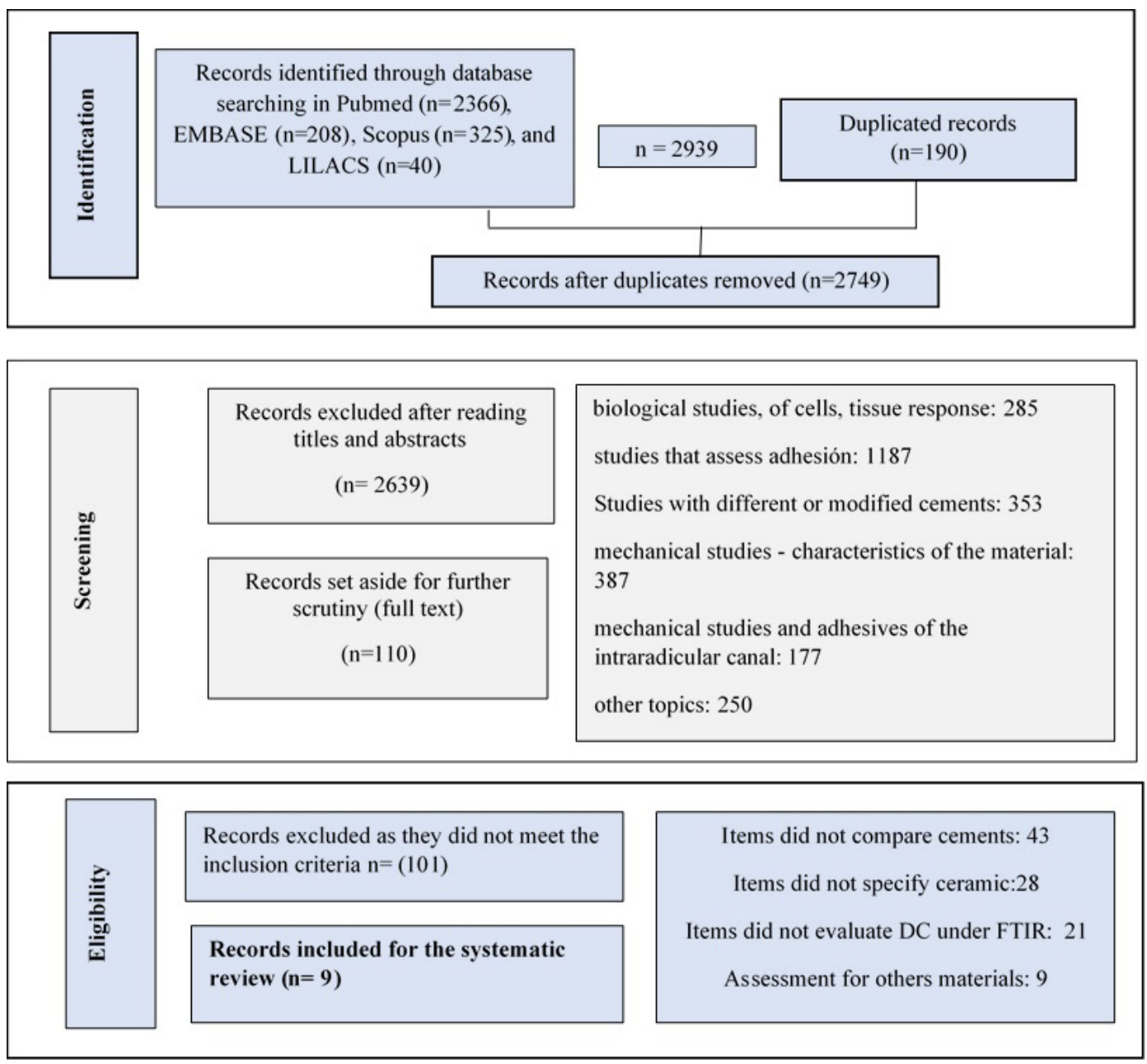

Fig. 1. Flowchart of searching and selection process of articles in the systematic review.

Table 2. Application of guidelines for reporting preclinical in vitro studies on dental materials for the selected studies in the systematic review $(n=9)$.

\begin{tabular}{|c|c|c|c|c|c|c|c|c|c|c|c|c|c|c|c|}
\hline \multirow{2}{*}{ Study } & \multicolumn{15}{|c|}{ Ítem Ítem Ítem Ítem Ítem Ítem Ítem Ítem Ítem Ítem Ítem Ítem Ítem Ítem Ítem } \\
\hline & 1 & $2^{\mathrm{a}}$ & $2 \mathrm{~b}$ & 3 & 4 & 5 & 6 & 7 & 8 & 9 & 10 & 11 & 12 & 13 & 14 \\
\hline Calgaro PA et al., 2013[5] & () & $\ominus$ & $\ominus$ & ( & $\ominus$ & ( & $\ominus$ & $\otimes$ & $\otimes$ & $\otimes$ & $\ominus$ & () & $\otimes$ & $\otimes$ & $\otimes$ \\
\hline Cho SH et al., 2015[6] & $\Theta$ & $\Theta$ & $\Theta$ & 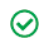 & $\ominus$ & $\Theta$ & $\ominus$ & $\otimes$ & $\otimes$ & $\otimes$ & $\Theta$ & ( & $\Theta$ & $\otimes$ & $\otimes$ \\
\hline Scotti N et al., 2016[3] & () & ( & ( & $\ominus$ & $\ominus$ & ( ) & $\ominus$ & $\otimes$ & $\otimes$ & $\otimes$ & $\ominus$ & () & $\otimes$ & $\otimes$ & $\otimes$ \\
\hline Hoorizad Ganjkar M et al., 2017[18] & $\Theta$ & $\Theta$ & $\Theta$ & $\oslash$ & $\ominus$ & $\Theta$ & $\ominus$ & $\otimes$ & $\otimes$ & $\otimes$ & $\Theta$ & $\Theta$ & $\otimes$ & $\otimes$ & $\otimes$ \\
\hline Novais VR et al., 2017[1] & ( & ( & ( & $\odot$ & ( ) & $\Theta$ & ( ) & $\otimes$ & $\otimes$ & $\otimes$ & ( & ( & $\otimes$ & ( ) & $\otimes$ \\
\hline Alkhudhairy F et al., 2018[7] & $\Theta$ & $\Theta$ & $\Theta$ & $\ominus$ & $\Theta$ & $\Theta$ & $\Theta$ & $\otimes$ & $\otimes$ & $\otimes$ & $\Theta$ & ( & $\Theta$ & $\Theta$ & $\otimes$ \\
\hline Donmez MB et al., 2019[24] & () & () & () & 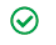 & ( & $\Theta$ & ( & $\otimes$ & $\otimes$ & $\otimes$ & $\ominus$ & () & $\ominus$ & 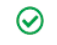 & $\otimes$ \\
\hline de Jesus RH et al., 2020[25] & () & ( & ( & $\ominus$ & ( & ( ) & ( & $\otimes$ & $\otimes$ & $\otimes$ & $\odot$ & () & $\odot$ & () & $\otimes$ \\
\hline Liporoni PCS et al., 2020[26] & () & $\theta$ & $\theta$ & ( & $\theta$ & ( ) & $\theta$ & $\otimes$ & $\otimes$ & $\propto$ & ( & $(2)$ & $\otimes$ & $\theta$ & $\otimes$ \\
\hline
\end{tabular}

Quality evaluation: $\odot$ fills the requirement, $\otimes$ Does not fill the requirement

$1.400 \mathrm{~mW} / \mathrm{cm}^{2}$, and $2.300 \mathrm{~mW} / \mathrm{cm}^{2}$, respectively. The minimum curing time was $15 \mathrm{~s}$ [6] and the maximum was $60 \mathrm{~s}$. [3] Two studies reported a waiting time between the application of dual cement and photoactivation to allow the self-polymerization reaction. [1,7] Three studies evaluated the transmission of light through ceramic discs of different thicknesses. [6,24,25]
Two of the nine included in vitro studies $[5,26]$ compared different types and opacities of ceramics, reporting a higher DC for light-cured types of cement, although there were no significant differences concerning the ceramic thickness and the same behavior in more translucent ceramics. Conversely, de Jesus et al. [25] showed no differences in the final DC for light-cured cement using different translucent ceramics, and the dual-cured cement showed the best 
Table 3. Data of the articles included $(n=9)$

\begin{tabular}{|c|c|c|c|c|c|c|c|c|c|}
\hline Author, year and country & Ceramic & Shade & $\begin{array}{c}\begin{array}{c}\text { Thickness } \\
(\text { millimeter } \\
\mathrm{mm})\end{array} \\
\end{array}$ & Resin cement & $\begin{array}{c}\text { Activation } \\
\text { mode }\end{array}$ & $\begin{array}{c}\text { Cement } \\
\text { thickness } \\
\text { (microns) } \mu \\
\end{array}$ & Lamp & $\begin{array}{l}\text { Curing time } \\
\text { (seconds) sec }\end{array}$ & $\begin{array}{l}\text { Results } \\
\% \text { DC }\end{array}$ \\
\hline & & & 1.5 & RelyX Veneer & & & & & $66.9 \pm 4.3$ \\
\hline & IPS InLine, & & 2.0 & (3M ESPE) & Photo & & & & $65.4 \pm 3.4$ \\
\hline & (Ivoclar-Vivadent) & A2 & 1.5 & & & & & & $61.0 \pm 2.7$ \\
\hline & & & 2.0 & Variolink II (Ivoclar) & Dual & & & & $66.3 \pm 2.8$ \\
\hline & & & 1.5 & & & & & & $64.5 \pm 2.2$ \\
\hline & & & 2.0 & RelyX Veneer (3M) & Photo & & & & $67.4 \pm 1.8$ \\
\hline & & A2 HT & 1.5 & & & & & & $64.8 \pm 3.1$ \\
\hline Calgaro PA et al., 2013[5] & & & 2.0 & Variolink II (Ivoclar) & Dual & & LED Translux Power Blue & & $63.5 \pm 0.4$ \\
\hline Brazil. & & & 1.5 & & & $100 \mu$ & $1000 \mathrm{~mW} / \mathrm{cm}^{2}$ & $40 \mathrm{sec}$ & $67.4 \pm 1.1$ \\
\hline & IPS E.max Press & & 2.0 & RelyX Veneer (3M) & Photo & & & & $61.0 \pm 4.3$ \\
\hline & (Ivoclar-Vivadent) & A2 LT & 1.5 & & & & & & $58.7 \pm 2.2$ \\
\hline & & & 2.0 & Variolink II (Ivoclar) & Dual & & & & $60.1 \pm 2.2$ \\
\hline & & & 1.5 & & Photo & & & & $67.8 \pm 1.8$ \\
\hline & & $A 2 M O$ & 2.0 & RelyX Veneer (3M) & Photo & & & & $64.1 \pm 1.2$ \\
\hline & & $A \angle M O$ & 1.5 & & & & & & $55.0 \pm 2.5$ \\
\hline & & & 2.0 & Variolink II (Ivoclar) & Dual & & & & $56.5 \pm 3.7$ \\
\hline & & & 0.3 & & & & & & $34.8 \pm 12.8$ \\
\hline & & & 0.6 & & & & & & $32.7 \pm 6.4$ \\
\hline & & & 0.9 & Nexus 3 DC (Kerr) & Dual & & & & $28.5 \pm 8.8$ \\
\hline Cho SH et al., 2015[6] & E.max Press; & $010 \mathrm{~T}$ & 1.2 & & & & LED Demi Plus; Kerr & $15 \mathrm{coc}$ & $14.0 \pm 7.4$ \\
\hline USA & (Ivoclar Vivadent) & Al LI & 0.3 & & & - & $900 \mathrm{~mW} / \mathrm{cm} 2$ & $15 \mathrm{sec}$ & $32.2 \pm 8.7$ \\
\hline & & & 0.6 & Nexus 3 I C (Kerr) & Photo & & & & $29.6 \pm 5.9$ \\
\hline & & & 0.9 & Nexus s LC (Kerr) & Pnoto & & & & $29.2 \pm 8.1$ \\
\hline & & & 1.2 & & & & & & $28.9 \pm 7.5$ \\
\hline & & & 0.0 & & & & & & $53.9 \pm 10.3$ \\
\hline & & & 0.6 & & & & & & $54.6 \pm 2.1$ \\
\hline & & & 1.0 & Nexus 3 DC (Kerr) & Dual & & & & $42.7 \pm 2.5$ \\
\hline Scotti $N$ et al. 2016[3] & IPS e.max CAD & & 1.5 & & & & LED polywave Valo, & $60 \operatorname{ser}$ & $47.4 \pm 16.2$ \\
\hline Italy & (Ivoclar-Vivadent) & $\mathrm{A} 2 \mathrm{LI}$ & 0.0 & & & $170 \mu$ & $1400 \mathrm{~mW} / \mathrm{cm} 2$ & $60 \mathrm{sec}$ & $56.26 \pm 2.3$ \\
\hline & & & 0.6 & Choice 2 (Bisco) & Photo & & & & $60.9 \pm 5.3$ \\
\hline & & & 1.0 & Cholce 2 (BISco) & Photo & & & & $58.4 \pm 4.4$ \\
\hline & & & 1.5 & & & & & & $53.4 \pm 7.2$ \\
\hline & & & 0.0 & & & & & & 70.74 \\
\hline & & & 0.5 & & & & & & 68.67 \\
\hline & & & 1.0 & Choice2 (Bisco) & Photo & & & & 71.06 \\
\hline Hoorizad Ganjkar M et al., & IPS Empress ceramic & & 1.5 & & & 50 & LED Demetron II Kerr, & & 72.51 \\
\hline & (Ivoclar; Vivadent) & A2 & 0.0 & & & so $\mu$ & $600 \mathrm{~m} \mathrm{~W} / \mathrm{cm} 2$ & $40 \mathrm{sec}$ & 65.38 \\
\hline & & & 0.5 & Nexus 3 (Kerr) & Dual & & & & 69.60 \\
\hline & & & 1.0 & Nexus 3 (Kerr) & Dual & & & & 69.64 \\
\hline & & & 1.5 & & & & & & 69.24 \\
\hline & & A3 & 1.0 & $\begin{array}{l}\text { Variolink II (Ivoclar) } \\
\text { paste + catalyst }\end{array}$ & Dual & & & & $65.7(2.9)$ \\
\hline & Super Porcelain & $\mathrm{A} 3$ & 1.0 & Variolink II (Ivoclar) & Photo & & & & $58.3(2.1)$ \\
\hline $\begin{array}{l}\text { Novais VR et al., 2017[1] } \\
\text { Brazil }\end{array}$ & $\begin{array}{l}\text { EX-3 Speed, Enamel } \\
\text { S3, (Noritake Dental }\end{array}$ & A3 & 1.0 & $\begin{array}{l}\text { RelyX ARC (3M) } \\
\text { paste + catalyst }\end{array}$ & Dual & $1000 \mu$ & $\begin{array}{l}\text { QTH, Optilux 501, Kerr; } \\
800 \mathrm{~mW} / \mathrm{cm} 2\end{array}$ & $40 \mathrm{sec}$ & $72.8(3.7)$ \\
\hline & Supply) & A3 & 1.0 & RelyX ARC (3M) & Photo & & & & $57.5(4.4)$ \\
\hline & & +3 & 1.0 & $\begin{array}{c}\text { Variolink Veneer } \\
\text { (Ivoclar) }\end{array}$ & Photo & & & & $48.6(4.1)$ \\
\hline & & & & Variolink E (ivoclar) & Photo & & & & 87.185 \\
\hline Alkhudhairy F et al., 2018[7] & IPS Emax, Ivoclar & ..--. & 10 & $\begin{array}{c}\text { Nexus } 3 \text { LC (Kerr) } \\
\end{array}$ & Photo & $1.000 u$ & LED Woodpecker I & $40 \mathrm{sec}$ & 75.919 \\
\hline Saudi Arabia & Vivadent & ---- & 1.0 & Variolink N (ivoclar) & Dual & $1.000 \mu$ & $2.300 \mathrm{~mW} / \mathrm{cm} 2$ & $40 \mathrm{sec}$ & 44.556 \\
\hline & & & & Calibra (Dentsply) & Dual & & & & 61.525 \\
\hline & & & 0.0 & & & & & & 70.0 \\
\hline & & & 0.5 & & & & & & 65.4 \\
\hline & & & 1.0 & Variolink Esthetic LC & Photo & & & & 64.3 \\
\hline & & & 1.5 & & & & & & 56.9 \\
\hline Donmez MB et al., 2019[24] & IPS Empress CAD & HTA2 & 2.0 & & & $170 \mu$ & LED Bluephase & 20 ser & 55.3 \\
\hline Turkey & (Ivoclar Vivadent) & $\mathrm{HI}$ AL & 0.0 & & & $1 / 0 \mu$ & $\begin{array}{l}\text { (IVoclar) } \\
\text { (1200/m/ } / \mathrm{cm} \text { ) }\end{array}$ & $20 \mathrm{sec}$ & 69.5 \\
\hline & & & 0.5 & & & & & & 67.1 \\
\hline & & & 1.0 & Variolink Esthetic DC & Dual & & & & 66.0 \\
\hline & & & 1.5 & & & & & & 60.8 \\
\hline & & & 2.0 & & & & & & 59.2 \\
\hline & & $\mathrm{HT}$ & 0.0 & RelyX ARC & Dual & & & & 80.5 \\
\hline & & $\mathrm{HI}$ & 1.5 & (3M ESPE) & Dual & & & & 82.9 \\
\hline & & HT & 0.0 & RelyX Veneer & Photo & & & & 73.9 \\
\hline & & HI & 1.5 & (3M ESPE) & Photo & & & & 74.1 \\
\hline & & & 0.0 & RelyX ARC & & & & & 80.5 \\
\hline de Jesus RH et al., 2020 & IPS e.max Press & LT & 1.5 & (3M ESPE) & Dual & $300 \mu$ & LED Bluephase G2 - & 40 ser & 80.3 \\
\hline Brazil[25] & (Ivoclar-Vivadent) & IT & 0.0 & RelyX Veneer & Photo & $300 \mu$ & $1218 \mathrm{~mW} / \mathrm{cm} 2$ & $40 \mathrm{sec}$ & 73.9 \\
\hline & & $\mathrm{LI}$ & 1.5 & (3M ESPE) & Photo & & & & 73.3 \\
\hline & & $M O$ & 0.0 & & & & & & 80.5 \\
\hline & & MIO & 1.5 & (3M ESPE) & Dual & & & & 83.9 \\
\hline & & $\mathrm{MO}$ & 0.0 & RelyX Veneer & Photo & & & & 73.9 \\
\hline & & MIO & 1.5 & (3M ESPE) & Photo & & & & 74.6 \\
\hline & & & 0.0 & & & & & & 53.07 \\
\hline & & HT & 0.5 & Variolink Esthetic LC & Phott & & & & 53.63 \\
\hline & & $\mathrm{HI}$ & 1.0 & Light+ (ivoclar) & Pnoto & & & & 53.04 \\
\hline & & & 2.0 & & & & & & 51.28 \\
\hline & & & 0.0 & & & & & & 46.52 \\
\hline & & & 0.5 & RelyX Ultimate A1 & & & & & 46.18 \\
\hline & & HT & 1.0 & (3M ESPE) & Dual & & & & 46.48 \\
\hline Liporoni PCS et al., 2020 & IPS e.max CAD & & 2.0 & & & $500 \mu$ & LED Bluephase G2 - & 40 ser & 45.99 \\
\hline Brazil[26] & (Ivoclar-Vivadent) & & 0.0 & & & $500 \mu$ & $1200 \mathrm{~mW} / \mathrm{cm} 2$ & $40 \mathrm{sec}$ & 53.07 \\
\hline & & & 0.5 & Variolink Esthetic LC & & & & & 52.74 \\
\hline & & LT & 1.0 & Light+ (ivoclar) & Photo & & & & 53.30 \\
\hline & & & 2.0 & & & & & & 51.30 \\
\hline & & & 0.0 & & & & & & 46.52 \\
\hline & & & 0.5 & RelyX Ultimate A1 & & & & & 45.17 \\
\hline & & LT & 1.0 & (3M ESPE) & Dual & & & & 46.33 \\
\hline & & & 2.0 & & & & & & 44.92 \\
\hline
\end{tabular}


results. Cho et al. [6] showed a decrease in the DC with a greater ceramic thickness. However, no statistically significant differences were found between the light-cured and dual-cured cements with thicknesses of $0.3,0.6$, and $0.9 \mathrm{~mm}$. The subgroup of dual-cured resin cement of $1.2 \mathrm{~mm}$ showed a significantly lower DC than the light-cured subgroup. [6] Scotti et al. [3] found that light-cured cement had a significantly better performance than dual-cured cement when e.max CAD discs (Ivoclar; Vivadent) from 0.6 to $1.5 \mathrm{~mm}$ were used. Donmez and Yucel showed a decrease in the DC with a greater ceramic thickness in both cements, without statistically significant differences. [24] In addition, Alkhudhairy et al. [7] obtained higher percentages of DC for light-cured cements.

Hoorizad Ganjkar et al. [18] found no statistically significant differences in the DC of light- and dual-cured resin cements between the control and experimental groups of feldspathic ceramics (IPS Empress-Ivoclar; Vivadent) with thicknesses up to $1.5 \mathrm{~mm}$ (the maximum thickness evaluated). Finally, Novais et al. [1] and de Jesus et al. [25] observed that resin cements used in dual-activation mode (base and catalyst) showed higher DC values, while the light-cured resin cement showed lower DC values.

\subsection{Methodological considerations and limitations provided for the included studies}

Table 4 shows the limitations of the analysis of the studies included in this systematic review. The majority of these considerations refer to the main characteristics considering the design for in vitro studies; in other cases, gaps in knowledge were found, and further research is required to increase the scientific evidence through standardized methods and take into account other possible variables and statistical analyses.

\section{Discussion}

An inadequate DC is associated with a lower performance of resin cement, leading to undesirable clinical results, such as microfiltration, increased water sorption, reduced color stability, postoperative sensitivity, and deficient mechanical properties, among other factors involved in the failure of restorative treatment. [27] The decision to include studies that used FTIR to evaluate the DC of resinous cements was mainly based on the fact that it is one of the most commonly used objective methods in resin-based restorative materials, as it generates detailed and consistent results of the DC throughout the structure, when detecting the stretching vibrations of carboncarbon double bonds involved in polymerization. [4,28,29]

The type of cement significantly influenced the DC values in seven of the nine included studies. Scotti et al., [3] Calgaro et al., [5] Cho et al., [6] Alkhudhairy et al., [7] and Liporoni et al. [26] observed higher DC values when light-cured cements were used compared to dual cements, even at a thickness of $2 \mathrm{~mm}$. [5] Hoorizad Ganjkar et al. [18] reported similar results without statistically significant differences in the DC of light-cured and dual-cured cements. They showed an increase in the DC percentage for light-cured cements, [18] supporting the use of light-cured cement in ceramic restorations with these thicknesses. Although studies comparing light-cured and dual-cured cements are limited, there are publications supporting light-cured cements for ceramic restorations of different thicknesses. Rizzante et al. [27] analyzed the DC of a light-cured cement (Variolink veneer) using lithium disilicate spacers IPS E-max CAD (HT A1) and found a similar DC for the control group when evaluated with FTIR immediately after curing. Yuh et al. [30] concluded that ceramics with thicknesses of $0.5,1.0$, and $1.5 \mathrm{~mm}$ did not have a significant effect on the lightcured resin cement DC compared with the control group. Furuse et al. [31] did not observe statistically significant differences in the flowable resin DC under ceramics (IPS classic-Ivoclar) with thicknesses of $0.5,0.7$, and $1 \mathrm{~mm}$, indicating that polymerization of the resins was adequate when the ceramic material was interposed.

The studies conducted by Novais et al. [1] and de Jesus et al. [25] found a higher DC in dual-resin cements with dual activation mode (base and catalyst), followed by light-activation mode (base paste only), and the lowest DC for light-curing resin cement. These findings confirm the importance of chemical activation in dual-cured resin cements and reinforce that the promotion of correct photopolymerization is a determinant to guarantee an adequate $D C$, because the component of self-curing by itself is insufficient. [3,5,6,18,32,33] This situation has been demonstrated by some studies that found low DC values (10.82\% to $24.93 \%$ ) when evaluating resinous cements at 10 min of curing only with chemical activation. [34] For instance, Aguiar et al., [35] Meng et al., [11] Lancellotti et al., [36] and Lee et al. [37] concluded that the total absence of photoactivation can deteriorate the mechanical properties of cement compared with the dualpolymerization mode.

The discrepancies in the behavior of both types of cements evaluated under the same conditions may be due to differences in the composition, amount of chemical activator, photoinitiators, type of monomers, fill volume, size and shape of particles, refractive indices, and dispensing mode (accepting the theory that manual mixing pastes can incorporate air bubbles further inhibiting polymerization due to the presence of oxygen). [5,38,39] Two studies used more than one cement with the same polymerization mode. Novais et al. [1] compared two dual cements and found statistically significant differences in Variolink II and Relyx ARC resin cements evaluated with the same variables. In addition, Alkhudhairy et al. [7] found differences between the two light-cured cements (Variolink E and Nexus 3 LC) and the two dual cements (Variolink $\mathrm{N}$ and Calibra).

Complementing the above, Lanza et al. [40] and Pereira et al. [41] reported similar results, supporting the idea that the discrepancies obtained in the DC may be due to the cement composition rather than its activation mode. Additionally, differences have been found between the categories of resin cement (conventional and selfadhesive). [41] Self-adhesive materials showed lower DC values in comparison with conventional resin cements, $[7,42]$ probably because of the increase in viscosity, which affects the migration ability of radicals and lowers $\mathrm{pH}$, which in turn can interfere with the kinetics of polymerization. $[7,43]$ To optimize the DC, self-adhesive cements may require a superior light-activation time than that recommended by the manufacturers. [44] The results listed above could have some cautious interpretations with the studies included in the systematic review, because the resinous cements used in the studies were conventional.

Regarding the characteristics of interposed ceramics, the DC can be more affected by the thickness and microstructure than by the shade of the ceramic. $[1,45,46]$ Cho et al. [6] found a statistically significant decrease in DC related to the increase in ceramic thickness but only in the case of dual-cured cements. Donmez and Yucel [24] found a decrease in DC in both light- and dual-cured cements with an increase in ceramic thickness. Three studies compared different opacities for the same type of ceramic. $[5,25,26]$ de Jesus et 
Table 4. Limitations of the articles included in the systematic review $(n=9)$

\begin{tabular}{|c|c|}
\hline Study & Limitations \\
\hline Calgaro PA et al., 2013[5] & $\begin{array}{l}\text { They do not report how much time was expected after curing to measure DC. } \\
\text { It does not simulate oral conditions. } \\
\text { It does not refer storage conditions of materials. } \\
\text { It does not refer storage conditions of samples. } \\
\text { They mention lamp intensity but they do not report calibration. } \\
\text { The lamp distance to the ceramic disc is not reported } \\
\text { They do not report lamp activation protocol. }\end{array}$ \\
\hline Cho SH et al., 2015[6] & $\begin{array}{l}\text { Dry storage does not simulate oral conditions. } \\
\text { No thickness of the cement layer is reported. } \\
\text { The lamp distance to the ceramic disc is not reported } \\
15 \text { seconds of polymerization. } \\
\text { It does not refer storage conditions of materials. } \\
\text { It does not refer to the dispensing protocol of the cementation materials or light activation. }\end{array}$ \\
\hline Scotti N et al. 2016[3] & $\begin{array}{l}\text { It does not simulate oral conditions. } \\
\text { The readings of both cements were made } 10 \text { minutes after photopolymerization. } \\
\text { Thickness of } 170 \text { microns slightly higher than clinically employed } \\
\text { They mention the lamp intensity but they do not report calibration. } \\
\text { It does not refer to storage conditions or protocol for dispensing cementing materials. }\end{array}$ \\
\hline $\begin{array}{l}\text { Hoorizad Ganjkar M et al., } \\
\text { 2017[18] }\end{array}$ & $\begin{array}{l}\text { It does not simulate oral conditions. } \\
\text { They do not report how much time was expected after curing to measure DC. } \\
\text { It does not refer storage conditions of materials. } \\
\text { It does not refer storage conditions of samples. } \\
\text { They mention lamp intensity but they do not report calibration. } \\
\text { They do not report lamp activation protocol. }\end{array}$ \\
\hline Novais VR et al., 2017[1] & $\begin{array}{l}\text { Only one ceramic thickness was evaluated. } \\
\text { Thickness cement layer, does not correspond to the space required for cement in clinical practice. } \\
\text { It does not refer storage conditions of materials. } \\
\text { Dual cement for manual mixing. } \\
\text { Dry storage does not simulate oral conditions. } \\
\text { They mention lamp intensity but they do not report calibration. } \\
\text { Value }+3 \text { of the light-curing cement ( } 5 \% \text { translucency). }\end{array}$ \\
\hline Alkhudhairy F et al., 2018[7] & $\begin{array}{l}\text { It does not simulate oral conditions. } \\
\text { Thickness cement layer } 1.000 \text { microns } \\
\text { Does not specify whether the ceramic is CAD or press } \\
\text { Only one ceramic thickness was evaluated. } \\
\text { They mention lamp intensity but they do not report calibration. } \\
\text { It does not refer storage conditions of materials. } \\
\text { It does not refer storage conditions of samples. } \\
\text { They do not report how much time was expected after curing to measure DC. }\end{array}$ \\
\hline Donmez MB et al., 2019[24] & $\begin{array}{l}\text { The lamp distance to the ceramic disc is not reported } \\
\text { They do not report the lamp activation protocol. } \\
\text { They mention lamp brand but they do not report its intensity. } \\
\text { They used a glass plates between ceramic and cement layer. } \\
\text { They do not specify the glass plate size } \\
\text { They do not explain the used of dark chamber }\end{array}$ \\
\hline de Jesus RH et al., 2020[25] & $\begin{array}{l}\text { It does not refer storage conditions of materials. } \\
\text { Thickness cement layer, does not correspond to the space required for cement in clinical practice. } \\
\text { It does not refer to the dispensing protocol of the cementation materials }\end{array}$ \\
\hline Liporoni PCS et al., 2020[26] & $\begin{array}{l}\text { Thickness cement layer, does not correspond to the space required for cement in clinical practice. } \\
\text { It does not refer storage conditions of materials. } \\
\text { Dry storage of samples does not simulate oral conditions. } \\
\text { They mention lamp intensity but they do not report calibration. } \\
\text { The lamp distance to the ceramic disc is not reported } \\
\text { It does not refer to the dispensing protocol of the cementation materials or light activation }\end{array}$ \\
\hline
\end{tabular}

al. [25] and Liporoni et al. [26] found the same behavior in the DC for different shades and thicknesses of ceramic, although no statistically significant differences were observed. Specifically, Liporoni et al. [26] found a higher DC in light-cured cement and de Jesus et al. [25] in dual-cured cement. These results match those of other studies that did not show statistically significant differences in the DC for ceramics with different shades and thicknesses. [31] The ceramic microstructure affects the amount of light reaching the cement, thus reducing its DC. [32] Calgaro et al., [5] Lanza et al., [40] Majumder et al., [46] and Turp et al. [47] found a higher DC when using high-glasscontent ceramics compared with polycrystalline ceramics. Cardash et al. showed that using a high-chroma ceramic can negatively influence polymerization [48] because the pigments can absorb light, affecting its reach to the cement. [49]

A reduction in DC may also occur because of the photoactivation-specific process. [50] The factors to be considered are the light intensity (usually decreases when placing a ceramic material), [6,51] 
the lamp wavelength (must be coincident with photoinitiators), and the activation protocols. [52] Cho et al. [6] reported DC values below $35 \%$ (clinically unacceptable). This could be explained by the use of a short irradiation time and low power (15 s irradiation with an LED lamp of $900 \mathrm{~mW} / \mathrm{cm}^{2}$ ). Martins et al. [53] established that curing times below $20 \mathrm{~s}$ require powers between 3200 and $3500 \mathrm{~mW} / \mathrm{cm}^{2}$ for an acceptable DC. Cho et al. [6] did not report in their study aspects such as the cement layer thickness, light-activation protocol specificities, and lamp distance, which according to studies, should be as close as possible. [54-56] Novais et al. [1] also found low values of DC when they evaluated the Variolink Veneer cement +3 , possibly due to the low translucency of the cement ( $5 \%$ translucency reported by the commercial brand), a thick cement layer $(1000 \mu \mathrm{m})$, and a lack of lamp calibration during the study. Finally, Scotti et al. [3] and Liporoni et al. [26] reported a DC below $60 \%$ for both cements, even in the control group, and Alkhudhairy et al. [7] for Variolink N, but there was no specific information regarding the factors involved.

The type of lamp plays an important role in the polymerization of resinous cements. Several studies have reported an increase in DC when they are light-cured with an LED lamp in comparison with other light sources. $[57,58]$ Polywave lamps emit light with two or more wavelength ranges, providing advantages, especially in cases where there is more than one photoinitiator or when the manufacturers omit the type of photoinitiator used. These lamps are generally recommended for their ability to activate a wide range of photoinitiators. $[59,60]$ The cementation protocol also influences DC. The handling of materials, the working time, the setting time, and the time necessary for the beginning of photopolymerization, could affect the mechanical properties of cement and the clinical behavior of the cemented indirect restorations. [41] Therefore, it is necessary to follow the protocols described by the manufacturers to optimize the polymerization of cements.

Finally, the time between curing and determining the DC can also modify the results. Post-polymerization reactions consist of continuous conversion of monomers, even after the photopolymerization process. [61] The conversion of monomers retains a free radical at the end of the polymer chain, which can trigger other monomeric molecules and increase the number of cross-links. DC measurements taken immediately after photopolymerization could yield unreliable results, as shown by Aguiar et al., [35] Giannini et al., [62] and Rizzante et al. [27]

The limitations of this review include the type and insufficient number of studies comparing light-cured and dual-cured cements under vitreous ceramics using the same variables, the heterogeneity in the study protocols, and the absence of specific data involved in the photopolymerization process.

\section{Conclusion and recommendations}

According to the results of this review, light-curing cements showed better DC in relation to dual cements in vitreous ceramic restorations of up to $2 \mathrm{~mm}$. These favorable properties of the lightcuring cement must be accompanied by an adequate photopolymerization protocol, following the manufacturer's recommendations. The discrepancies obtained in the DC could be influenced by the composition of the cement in addition to the activation mode.

As mentioned above, many variables affect the $D C$ of resinous cement; more standardized studies are required, with complete in- formation regarding dispensing protocols, materials and sample storage, curing time, power, distance, wavelength, and lamp calibration, following the protocols recommended by manufacturers and recreating conditions closely comparable to those required in the clinical environment. The measurement of the DC should be objective, such as that in the studies included in this review. Finally, the measurements in both cements should be conducted after a prudent time of at least $24 \mathrm{~h}$ to obtain more reliable DC data.

\section{Other aspects for this systematic review}

\subsection{Study protocol and registration}

The study was approved by the Ethics Committee of the Faculty of Dentistry of the University of Antioquia (Act 2/2017). The study protocol was registered at the International Prospective Register of Systematic Reviews (PROSPERO) (CRD42017069319, available from: http://www.crd.york.ac.uk/PROSPERO_REBRANDING/display_ record.asp?ID=CRD42017069319). The only amendment made to the information provided at registration or in the protocol registered in PROSPERO was the updating of the search period.

\section{Conflicts of interest}

The authors declare no conflict of interest.

\section{References}

[1] Novais VR, Raposo LH, Miranda RR, Lopes CC, Simamoto PCJ, Soares CJ. Degree of conversion and bond strength of resin-cements to feldspathic ceramic using different curing modes. J Appl Oral Sci 2017;25(1):61-8. https://doi.org/10.1590/1678-77572016-0221, PMID:28198977

[2] Peumans $M$, Van Meerbeek B, Lambrechts $P$, Vanherle G. Porcelain veneers: a review of the literature. J Dent 2000;28(3):163-77. https://doi.org/10.1016/ s0300-5712(99)00066-4, PMID:10709338

[3] Scotti N, Comba A, Cadenaro M, Fontanive L, Breschi L, Monaco C, et al. Effect of Lithium Disilicate Veneers of Different Thickness on the Degree of Conversion and Microhardness of a Light-Curing and a Dual-Curing Cement. Int J Prosthodont 2016;29(4):384-8. https://doi.org/10.11607/ijp.4811, PMID:27479348

[4] Cetindemir AB, Sermet B, Ongul D. The effect of light sources and CAD/CAM monolithic blocks on degree of conversion of cement. J Adv Prosthodont 2018;10(4):291-9. https://doi.org/10.4047/jap.2018.10.4.291, PMID:30140396

[5] Calgaro PA, Furuse AY, Correr GM, Ornaghi BP, Gonzaga CC. Influence of the interposition of ceramic spacers on the degree of conversion and the hardness of resin cements. Braz Oral Res 2013;27(5):403-9. https://doi. org/10.1590/s1806-83242013000500004, PMID:24036978

[6] Cho SH, Lopez A, Berzins DW, Prasad S, Ahn KW. Effect of Different Thicknesses of Pressable Ceramic Veneers on Polymerization of Light-cured and Dual-cured Resin Cements. J Contemp Dent Pract 2015;16(5):347-52. https:// doi.org/10.5005/jp-journals-10024-1688, PMID:26162252

[7] Alkhudhairy F, AlKheraif A, Naseem M, Khan R, Vohra F. Degree of conversion and depth of cure of Ivocerin containing photo-polymerized resin luting cement in comparison to conventional luting agents. Pak J Med Sci 2018;34(2):253-9. https://doi.org/10.12669/pjms.342.14491, PMID:29805389

[8] Gregor L, Bouillaguet S, Onisor I, Ardu S, Krejci I, Rocca GT. Microhardness of light- and dual-polymerizable luting resins polymerized through 7.5-mm-thick endocrowns. J Prosthet Dent 2014;112(4):942-8. https://doi. org/10.1016/j.prosdent.2014.02.008, PMID:24767899

[9] Arrais CA, Giannini M, Rueggeberg FA. Kinetic analysis of monomer conversion in auto- and dual-polymerizing modes of commercial resin luting cements. J Prosthet Dent 2009;101(2):128-36. https://doi.org/10.1016/s00223913(09)60008-1, PMID:19167537

[10] Gajewski VE, Pfeifer CS, Fróes-Salgado NR, Boaro LC, Braga RR. Monomers used in resin composites: degree of conversion, mechanical properties and water sorption/solubility. Braz Dent J 2012;23(5):508-14. https://doi. org/10.1590/s0103-64402012000500007, PMID:23306226 
[11] Meng X, Yoshida K, Atsuta M. Influence of ceramic thickness on mechanical properties and polymer structure of dual-cured resin luting agents. Dent Mater 2008;24(5):594-9. https://doi.org/10.1016/j.dental.2007.06.014, PMID:17669482

[12] Di Francescantonio M, Aguiar TR, Arrais CA, Cavalcanti AN, Davanzo CU, Giannini M. Influence of viscosity and curing mode on degree of conversion of dual-cured resin cements. Eur J Dent 2013;7(1):81-5. PMID:23407604

[13] Peutzfeldt A, Lussi A, Flury S. Effect of High-Irradiance Light-Curing on Micromechanical Properties of Resin Cements. Biomed Res Int 2016;2016:4894653. https://doi.org/10.1155/2016/4894653, PMID:28044129

[14] Archegas LR, de Menezes Caldas DB, Rached r N, Soares P, Souza EM. Effect of ceramic veneer opacity and exposure time on the polymerization efficiency of resin cements. Oper Dent 2012;37(3):281-9. https://doi. org/10.2341/11-134-I, PMID:22313282

[15] Kawai K, Iwami Y, Ebisu S. Effect of resin monomer composition on toothbrush wear resistance. J Oral Rehabil 1998;25(4):264-8. https://doi. org/10.1111/j.1365-2842.1998.00246.x, PMID:9610853

[16] Tanoue N, Koishi Y, Atsuta M, Matsumura H. Properties of dual-curable luting composites polymerized with single and dual curing modes. J Oral Rehabil 2003;30(10):1015-21. https://doi.org/10.1046/j.1365-2842.2003.01074.x, PMID:12974862

[17] Hofmann N, Renner J, Hugo B, Klaiber B. Elution of leachable components from resin composites after plasma arc vs standard or soft-start halogen light irradiation. J Dent 2002;30(5-6):223-32. https://doi.org/10.1016/s03005712(02)00022-2, PMID:12450713

[18] Hoorizad Ganjkar M, Heshmat H, Hassan Ahangari R. Evaluation of the Effect of Porcelain Laminate Thickness on Degree of Conversion of Light Cure and Dual Cure Resin Cements Using FTIR. J Dent (Shiraz) 2017;18(1):30-6. PMID:28280757

[19] Tantbirojn D, Chongvisal S, Augustson DG, Versluis A. Hardness and postgel shrinkage of preheated composites. Quintessence Int 2011;42(3):e51-9. PMID:21465004

[20] Runnacles P, Correr GM, Baratto Filho F, Gonzaga CC, Furuse AY. Degree of conversion of a resin cement light-cured through ceramic veneers of different thicknesses and types. Braz Dent J 2014;25(1):38-42. https://doi. org/10.1590/0103-6440201302200, PMID:24789290

[21] Faria ESAL, Pfeifer CS. Effectiveness of high-power LEDs to polymerize resin cements through ceramics: An in vitro study. JProsthet Dent 2017;118(5):6316. https://doi.org/10.1016/j.prosdent.2016.12.013, PMID:28385443

[22] Page MJ, McKenzie JE, Bossuyt PM, Boutron I, Hoffmann TC, Mulrow CD, et al. The PRISMA 2020 statement: An updated guideline for reporting systematic reviews. J Clin Epidemiol 2021;134:178-89. https://doi.org/10.1016/j. jclinepi.2021.03.001, PMID:33789819

[23] Faggion CM, Jr. Guidelines for reporting pre-clinical in vitro studies on dental materials. J Evid Based Dent Pract 2012;12(4):182-9. https://doi. org/10.1016/j.jebdp.2012.10.001, PMID:23177493

[24] Donmez MB, Yucel MT. Effect of monolithic CAD-CAM ceramic thickness on resin cement polymerization: An in-vitro study. Am J Dent 2019;32(5):240-4. PMID:31675192

[25] de Jesus RH, Quirino AS, Salgado V, Cavalcante LM, Palin WM, Schneider LF. Does ceramic translucency affect the degree of conversion of luting agents? Appl Adhes Sci 2020;8(1):4. https://doi.org/10.1186/s40563-02000127-2

[26] Liporoni PC, Ponce AC, de Freitas MR, Zanatta RF, Pereira MC, Catelan A. Influence of thickness and translucency of lithium disilicate ceramic on degree of conversion of resinous materials. J Clin Exp Dent 2020;12(8):e745-e8. https://doi.org/10.4317/jced.56921, PMID:32913571

[27] Rizzante FAP, Locatelli PM, Porto TS, Borges AFS, Mondelli RFL, Ishikiriama SK. Physico-mechanical properties of resin cement light cured through different ceramic spacers. J Mech Behav Biomed Mater 2018;85:170-4. https:// doi.org/10.1016/j.jmbbm.2018.06.001, PMID:29902777

[28] Mendonca LM, Ramalho IS, Lima L, Pires LA, Pegoraro TA, Pegoraro LF. Influence of the composition and shades of ceramics on light transmission and degree of conversion of dual-cured resin cements. J Appl Oral Sci 2019;27:e20180351. https://doi.org/10.1590/1678-7757-2018-0351, PMID:31365707

[29] Masood TM, Abbassy MA, Bakry AS, Matar NY, Hassan AH. Fourier-transform infrared spectroscopy/attenuated total reflectance analysis for the degree of conversion and shear bond strength of Transbond XT adhesive system. Clin Cosmet Investig Dent 2018;10:275-80. https://doi.org/10.2147/ccide. s169438, PMID:30584376
[30] Yuh C-S, Kim J-H, Kim S-J, Lee Y-K, Shim J-S. Comparison of the degree of conversion of light-cured resin cement in regard to porcelain laminate thickness, light source and curing time using FT-IR. J Korean Acad Prosthodont 2009;47(4):416-23. https://doi.org/10.4047/jkap.2009.47.4.416

[31] Furuse AY, Glir DH, Rizzante FAP, Prochnow R, Borges AFS, Gonzaga CC. Degree of conversion of a flowable composite light-activated through ceramics of different shades and thicknesses. Braz J Oral Sci 2015;14(3):230-3. https://doi.org/10.1590/1677-3225v14n3a11

[32] De Souza G, Braga RR, Cesar PF, Lopes GC. Correlation between clinical performance and degree of conversion of resin cements: a literature review. J Appl Oral Sci 2015;23(4):358-68. https://doi.org/10.1590/1678775720140524, PMID:26398507

[33] Arrais CA, Rueggeberg FA, Waller JL, de Goes MF, Giannini M. Effect of curing mode on the polymerization characteristics of dual-cured resin cement systems. J Dent 2008;36(6):418-26. https://doi.org/10.1016/j. jdent.2008.02.014, PMID:18395315

[34] Vrochari AD, Eliades G, Hellwig E, Wrbas KT. Curing efficiency of four selfetching, self-adhesive resin cements. Dent Mater 2009;25(9):1104-8. https:// doi.org/10.1016/j.dental.2009.02.015, PMID:19427029

[35] Aguiar TR, de Oliveira M, Arrais CA, Ambrosano GM, Rueggeberg F, Giannini $M$. The effect of photopolymerization on the degree of conversion, polymerization kinetic, biaxial flexure strength, and modulus of self-adhesive resin cements. J Prosthet Dent 2015;113(2):128-34. https://doi.org/10.1016/j. prosdent.2014.09.011, PMID:25432362

[36] Lancellotti A, Pacheco R, Gonçalves L, Giannini M. Filler particles analysis and degree of conversion of resin cements. Dent Mater 2014;30(1):e27. https://doi.org/10.1016/j.dental.2014.08.056

[37] Lee IB, An W, Chang J, Um CM. Influence of ceramic thickness and curing mode on the polymerization shrinkage kinetics of dual-cured resin cements. Dent Mater 2008;24(8):1141-7. https://doi.org/10.1016/j. dental.2008.03.015, PMID:18433858

[38] Lise DP, Van Ende A, De Munck J, Yoshihara K, Nagaoka N, Cardoso Vieira LC, et al. Light irradiance through novel CAD-CAM block materials and degree of conversion of composite cements. Dent Mater 2018;34(2):296-305. https://doi.org/10.1016/j.dental.2017.11.008, PMID:29169661

[39] Yan YL, Kim YK, Kim KH, Kwon TY. Changes in degree of conversion and microhardness of dental resin cements. Oper Dent 2010;35(2):203-10. https:// doi.org/10.2341/09-174-I, PMID:20420064

[40] Lanza MDS, Andreeta MRB, Pegoraro TA, Pegoraro LF, Carvalho RM. Influence of curing protocol and ceramic composition on the degree of conversion of resin cement. J Appl Oral Sci 2017;25(6):700-7. https://doi. org/10.1590/1678-7757-2016-0270, PMID:29211292

[41] Pereira SG, Fulgencio R, Nunes TG, Toledano M, Osorio R, Carvalho RM. Effect of curing protocol on the polymerization of dual-cured resin cements. Dent Mater 2010;26(7):710-8. https://doi.org/10.1016/j.dental.2010.03.016, PMID:20381853

[42] Moraes RR, Boscato N, Jardim PS, Schneider LF. Dual and self-curing potential of self-adhesive resin cements as thin films. Oper Dent 2011;36(6):63542. https://doi.org/10.2341/10-367-I, PMID:21864125

[43] Manso AP, Carvalho RM. Dental Cements for Luting and Bonding Restorations: Self-Adhesive Resin Cements. Dent Clin North Am 2017;61(4):821-34. https://doi.org/10.1016/j.cden.2017.06.006, PMID:28886770

[44] Almeida CM, Meereis CTW, Leal FB, Ogliari AO, Piva E, Ogliari FA. Evaluation of long-term bond strength and selected properties of self-adhesive resin cements. Braz Oral Res 2018;32:e15. https://doi.org/10.1590/18073107bor-2018.vol32.0015, PMID:29513888

[45] Fanfoni L, Marchesi G, Baccarini F, Turco G, Breschi L, Cadenaro M. Polymerization of dual resin cements light-cured through different ceramic materials. Dent Mater 2018;34:e46-e7. https://doi.org/10.1016/j.dental.2018.08.096

[46] Majumder A, Giri TK, Mukherjee S. An in vitro study to compare the influence of different all-ceramic systems on the polymerization of dual-cure resin cement. J Indian Prosthodont Soc 2019;19(1):58-65. https://doi.org/ 10.4103/jips.jips_262_18, PMID:30745755

[47] Turp V, Turkoglu P, Sen D. Influence of monolithic lithium disilicate and zirconia thickness on polymerization efficiency of dual-cure resin cements. J Esthet Restor Dent 2018;30(4):360-8. https://doi.org/10.1111/jerd.12390, PMID:30070739

[48] Cardash HS, Baharav H, Pilo R, Ben-Amar A. The effect of porcelain color on the hardness of luting composite resin cement. J Prosthet Dent 1993;69(6):620-3. https://doi.org/10.1016/0022-3913(93)90293-w, PMID:8320650 
[49] Barghi N, McAlister EH. LED and halogen lights: effect of ceramic thickness and shade on curing luting resin. Compend Contin Educ Dent 2003;24(7):497-500, 2, 4 passim; quiz 8. PMID:14508929

[50] Rasetto FH, Driscoll CF, von Fraunhofer JA. Effect of light source and time on the polymerization of resin cement through ceramic veneers. J Prosthodont 2001;10(3):133-9. https://doi.org/10.1111/j.1532-849x.2001.00133.x, PMID:11641840

[51] Peutzfeldt A, Asmussen E. Resin composite properties and energy density of light cure. J Dent Res 2005;84(7):659-62. https://doi.org/10.1177/ 154405910508400715, PMID:15972597

[52] Jimenez-Planas A, Martin J, Abalos C, Llamas R. Developments in polymerization lamps. Quintessence Int 2008;39(2):e74-84. PMID:18560645

[53] Martins FV, Vasques WF, Fonseca EM. How the Variations of the Thickness in Ceramic Restorations of Lithium Disilicate and the Use of Different Photopolymerizers Influence the Degree of Conversion of the Resin Cements: A Systematic Review and Meta-Analysis. J Prosthodont 2019;28(1):e395-e403. https://doi.org/10.1111/jopr.12920, PMID:29882387

[54] Zhu S, Platt J. Curing efficiency of three different curing modes at different distances for four composites. Oper Dent 2011;36(4):362-71. https://doi. org/10.2341/09-245-I, PMID:21834705

[55] Beolchi RS, Moura-Netto C, Palo RM, Rocha Gomes Torres C, Pelissier B. Changes in irradiance and energy density in relation to different curing distances. Braz Oral Res 2015;29. https://doi.org/10.1590/1807-3107bor-2015. vol29.0060, PMID:26017490
[56] Aromaa MK, Lassila LVJ, Vallittu PK. Effect of Distance on Light Transmission Through Polymerized Resin Composite. Eur J Prosthodont Restor Dent 2017;25(3):131-5. https://doi.org/10.1922/ejprd_01700aromaa05, PMID:28869366

[57] Ozakar Ilday N, Ziya Bayindir Y, Bayindir F, Gurpinar A. The effect of light curing units, curing time, and veneering materials on resin cement microhardness. J Dent Sci 2013;8(2):141-6. https://doi.org/10.1016/j.jds.2012.09.014

[58] Tanthanuch S, Kukiattrakoon B. The effect of curing time by conventional quartz tungsten halogens and new light-emitting diodes light curing units on degree of conversion and microhardness of a nanohybrid resin composite. J Conserv Dent 2019;22(2):196-200. https://doi.org/10.4103/jcd. jcd_498_18, PMID:31142993

[59] AlShaafi MM. Factors affecting polymerization of resin-based composites: A literature review. Saudi Dent J 2017;29(2):48-58. https://doi.org/10.1016/j. sdentj.2017.01.002, PMID:28490843

[60] Bakkal M, Yilmaz B, Durmus A, Durmus Z, Ozalp S. Polymerization characteristics of colored compomers cured with different LED units. J Appl Biomater Funct Mater 2019;17(1):2280800019827805. https://doi. org/10.1177/2280800019827805, PMID:30803300

[61] Furuse AY, Santana LOC, Rizzante FAP, Ishikiriama SK, Bombonatti JF, Correr GM, et al. Delayed Light Activation Improves Color Stability of Dual-Cured Resin Cements. J Prosthodont 2018;27(5):449-55. https://doi.org/10.1111/ jopr.12509, PMID:27455118

[62] Giannini M, Ayres A, Andre C, Sa R, Pacheco R, Carvalho A, et al. Curing conditions effects on degree of conversion of resin cement. Dental Materials 2012;28:e47. https://doi.org/10.1016/j.dental.2012.07.111

This is an open-access article distributed under the terms of Creative Commons Attribution-NonCommercial License 4.0 (CC BYNC 4.0), which allows users to distribute and copy the material in any format as long as credit is given to the Japan Prosthodontic Society. It should be noted however, that the material cannot be used for commercial purposes. 